\title{
LA NATURALEZA POLIÉDRICA DE LA LECTURA (A PROPÓSITO DEL DICCIONARIO DE NUEVAS FORMAS DE LECTURA Y ESCRITURA DE RED INTERNACIONAL DE UNIVERSIDADES LECTORAS)
}

\author{
Eloy Martos Núñez \\ Red Internacional de Universidades Lectoras \\ universidadeslectoras@gmail.com \\ Mar Campos Fernández-Fígares \\ Universidad de Almería \\ mcamposff@gmail.com
}

El Diccionario de nuevas formas de lectura y escritura, como su propio nombre indica, trata de abordar los nuevos fenómenos de lectura y escritura en relación con los modernos paradigmas científicos de las humanidades, las ciencias sociales, las tecnologías de la información y la comunicación, la biología y la ecología, etc. Esta visión holística de los procesos de lectura y escritura es fundamental para entender los cambios en procesos y concuerda con la filosofía de la Red de Universidades Lectoras, una red de más de 50 universidades de Europa y América que trabaja de forma transversal y multidisciplinar estas temáticas.

Este diccionario ha querido recuperar, pues, los conceptos de polifonía y dialogismo de Bajtin, para entender la pluralidad de manifestaciones a que estamos asistiendo y al juego dialógico entre las distintas concepciones, tecnologías y sectores o ámbitos implicados, desde los creadores a los profesores, desde las industrias o empresas culturales a la biblioteca o la sociedad de la información. Roger Chartier ha analizado magistralmente estas mutaciones que van desde la cultura impresa, con el concepto de libro y de canon de lecturas -que acotaba de forma precisa los soportes, géneros y usos del texto escrito-a la cultura electrónica, que ha supuesto una revolución profunda de todas estas prácticas. El texto electrónico o la lectura-escritura electrónica no son solo nuevas literacías que corresponden a nuevos alfabetismos: suponen mutaciones trascendentales en lo relativo a las prácticas de lectura, escritura y aprendizaje, como bien dice José Antonio Cordón, pues fomentan formas como la lectura fragmentaria o la lectura social, conectada, que se corresponden con la visión de Internet como una inteligencia o mente colectiva. Los textos, su uso, su percepción, es lo que cambia, pues ya no estamos solo ante formas tan "cristalizadas" como un manual o una novela -que son textos "acabados", lineales-, 
sino ante propuestas textuales que se leen y se (re)escriben de distinto modo, como le sucede a un hipertexto, o en el caso de la literatura y los medios, las sagas y series. También la percepción de un autor único se va haciendo borrosa precisamente gracias a la interactividad digital y a los nuevos géneros: el escritor "alógrafo" (A. Besson), el escrilector que recrea a partir de lo que lee (la fan fiction como ejemplo), el escritor amateur que hace continuamente "remix" igual que los internautas parodian y reescriben mensajes a partir de las herramientas 2.0.

Son cambios que tienen que ver, sin duda, con un nuevo tiempo en lo cultural, por ejemplo, la globalización y la posmodernidad como nuevas mentalidades, en lo tecnológico, con la sucesión de nuevos dispositivos de lectura, y en lo económico, con el surgimiento de nuevos modelos de negocio y la crisis del mercado del libro en cuanto a su cadena tradicional de producción-distribución-consumo que estudiaba la sociología de la lectura de Robert Escarpit y otros autores. El cambio de paradigma viene sin duda representado de forma emblemática por Internet, concebida como un "océano de información" que desborda fronteras, lenguas o culturas. Si entendemos la idea de "océano", "fluido" o "líquido" no como una figura metafórica de adorno, sino como una analogía que trata de aproximarnos a la realidad del fenómeno, entonces entenderemos mejor la dimensión de estos cambios.

Hemos asistido a una sorprendente convergencia entre literatura e informática, de modo que teorías como la que Julia Kristeva denominara en los años sesenta del siglo XX “escritura crucigramística” hoy son partes de las nuevas prácticas ciberliterarias. Lo importante es que esta aproximación nos permite ver el texto no como algo discontinuo o cerrado, sino como un continuum donde circulan los elementos a modo de flujo más que como -según la imagen estructuralista popularizada por Ferdinand de Saussureunas piezas de un ajedrez. El texto continuo, en efecto, desafía las viejas categorías de la cultura escrita y es la fuente de sagas, series, foros, etc. Claro que la idea de fluido es en cierto modo antagónica a la de texto (trenzado, tejido), como un cubo de hielo lo es a un vaso de agua, siendo ambas la misma sustancia.

Vemos, pues, un caso en que nociones del ámbito de la física, como fluido, partícula, fluctuación, escalamiento, percolación, transiciones de fase..., iluminan conceptos de lectura. Del mismo modo que la sociofísica u otras áreas científicas, las neurociencias hoy están arrojando luz sobre los procesos implicados, y nociones como inferencia, artefacto o sinestesia cobran nuevos matices. De hecho, Internet ha sido estudiada en esta doble dimensión de "artefacto" y de "cultura" (Christine Hine), pues por un lado ha generado un espacio propio, una cibercultura, pero a la par no deja de ser un gadget o artefacto sofístico que nos permite ampliar nuestro conocimiento del mundo al funcionar como una especie de "memoria externa", de prótesis cognitiva. Cierto que la percepción como artefacto es más compleja, porque constituye no un objeto único, sino varios dispersos (ordenadores, protocolos, programas...), pero más allá de su comprensión cabal, que solo es plena en algunos iniciados, lo importante es el uso social de esta herramienta, que ha explosionado con el auge actual de las redes sociales. Siguiendo con las analogías transdisciplinares que subyacen a este diccionario, estas redes sociales semejan las redes neuronales de nuestro cerebro, y nociones igualmente renovadoras como rizoma, fractal, performance, crossover, etc., iluminan las nuevas prácticas. 
Henry Jenkins ha definido con acierto los grandes ejes de la cibercultura en torno a dos conceptos sencillos de comprender: "convergencia de lenguajes" y "cultura participativa", o, dicho de otro modo, estamos en una época en que la lectura preferente ya no emana del logo-centrismo, al contrario, los mensajes están multicodificados, son multisensoriales (cf. concepto de sensorium) y ya no se organizan en torno al modelo de la linealidad de un libro impreso, sino que son más complejos y variados.

Compartimos con Liora Bresler la idea de que dos grandes ejes de la cultura contemporánea son el gusto por la ficción, por la narrativa, y la apropiación-personificación (embodiment) como actitud por la cual el lector acerca el texto a sus propios esquemas cognitivo y corporal y a sus circunstancias de recepción. La combinación de estos dos ejes explica el éxito de todo tipo de iniciativas en este sentido, por ejemplo, el fenómeno fan (y sus expresiones concretas: fan fiction, cosplay...) y el surgimiento "rizomático" de múltiples focos de cultura alternativa, con (re)creaciones locales de todo tipo de historias, que innovan o parodian series de televisión, videojuegos, best sellers y otras ficciones de éxito.

Los nuevos estudios de literacidad, la aproximación etnográfica, por ejemplo, a Internet y a la cultura contemporánea, y otros estudios culturales han hecho más borrosa la separación de géneros y de categorías, y han subrayado el papel de la ficción como lenguaje universal que recorre diferentes lenguajes y soportes. Hay que indagar las nuevas formas culturales y manifestaciones para poner en valor, tal como apunta Gustavo Bombini, "la diversidad de escenas de lectura y de los distintos modos en que la cultura escrita se convierte en objeto de apropiación". La pregunta sigue siendo la misma: cómo se puede configurar un corpus de prácticas letradas, qué parámetros usar atendiendo a estas nuevas prácticas y experiencias de lectura. Porque, frente al paradigma de la cultura impresa, lo cierto es que en el mundo actual cada vez se generan más prácticas, espacios e itinerarios de lectura tildados de inapropiados, no ya por la censura clásica de sus contenidos, sino de los nuevos formatos, ambientes y reglas de los propios eventos culturales. Prácticas inapropiadas equivalen, en este contexto, a irreverentes, imaginativas, transgresoras, marginales o contraculturales: un flasmov y muchas manifestaciones de la cultura jamming participarían de algunos de estos rasgos.

Lo específico de la idea de rizoma de los filósofos franceses (Deleuze y Guattari) viene a subrayar el papel de una red acéfala, asimétrica, multilocal y, por supuesto, desjerarquizada, lo cual contrasta con la visión centralizada de la cultura, focalizada en centros hegemónicos asociados a estatus de privilegio. Ocurría con las metrópolis respecto a los países colonizados, pero ocurría igual a muchos otros niveles: la capital de provincia respecto a los pueblos, el centro respecto a los barrios, la enseñanza académica frente a las no académicas, eran los mismos polos que marcaban un elemento superior y otro inferior. Internet se ha convertido en el "aula sin muros" que profetizó Mac Luhan y en esa aula no hay posiciones de privilegio, todos pueden pujar y todos, desde la horizontalidad, pueden conectarse e intercambiar cosas. Ya no es el árbol del conocimiento, erguido, vertical, con su tronco de raíces y un tronco del que se diversifica: la diversidad está ahora expandida a cualquier lugar, la verticalidad ha sido suplida por la horizontalidad, en cualquier sitio puede emerger la cepa o raíz, es como la mala hierba, que crece en los intersticios o márgenes de la realidad, de forma a menudo caótica. 


\section{LA LECTURA Y LA ESCRITURA EN LA ERA DIGITAL: CULTURA LETRADA Y MODERNIDAD}

Un espacio letrado en un contexto de sociedad de la información es por naturaleza híbrido y puede incorporar estas prácticas cercanas a la llamada transliteratura, así, por ejemplo, puede usar proyecciones manipuladas digitalmente o bien performances que empleen tecnología digital. Las "escrituras nómadas" (Belén Gache) de la era posletrada precisamente van en esta línea de usar soportes y espacios alternativos. Chartier traza una situación que explica en gran medida el fenómeno revolucionario francés: deterioro de las instancias de los poderes tradicionales y la aparición de una nueva conciencia ciudadana favorecida por la extensión de la alfabetización, la lectura y la cultura popular, que se contraponía al pensamiento del Estado, porque este no es rizomático, sino arbóreo, verticalista.

Los "brotes" expresarían, pues, el "magma oscuro creativo" que está en la base de los imaginarios sociales, según Castoriadis, y tiene ese carácter disperso y vinculado a la actuación, a las situaciones concretas. A este respecto, quizá ayude la Teoría del paréntesis de Gutenberg, formulada por el danés Sauenberg, aunque no es tanto una teoría como una hipótesis que intenta formular una comparación entre las culturas de la era anterior a la imprenta y de la era posletrada. En efecto, las formas de la transmisión de la cultura y la comunicación preimprenta y posinternet son muy similares. Antes de la aparición de la imprenta: inestable (las versiones orales cambiaban), colectivo (todo es de todos); performance (juglares con los cantares de gesta, la lectura en voz alta, etc.). Así pues, esta afinidad entre la cultura preletrada y la posletrada no es un retroceso, sino una recontextualización, o si le aplicamos la dialéctica de Hegel, un proceso completo de tesis-antítesis-síntesis, lo cual iría en consonancia con la conocida teoría de Walter Ong sobre la "oralidad secundaria".

Todo vuelve a ser colectivo, está la cultura de la apropiación, de la mezcla, el sampleo, el remix, etc.; y se vuelve a dar otra vez importancia a las formas orales, que habían sido despreciadas, relegadas durante ese paréntesis del dominio de la imprenta. En esta cultura posparéntesis, muchas producciones son remezcladas (remix), versionadas o mash-ups (es decir, hibridaciones) de cosas existentes anteriormente, lo cual nos devuelve a esa lucha entre libertad del arte, de la creatividad frente al derecho de autor, que es un imperativo legal, pero que cultural y antropológicamente no tiene mucho sentido, porque todo el arte deriva de otro anterior. Otra forma de lucha por la creatividad es la cultura jamming, que supone simplemente todas las manifestaciones de rebeldía, de resistencia contra la cultura popular aceptada. Se dedica a transformar los medios de comunicación de masas existentes a fin de generar un golpe negativo sobre ellos mismos, usando el mismo método de comunicación. Utilizan un medio, un arte, una obra y la desvirtúan para parodiar o criticar.

En todo caso, los nuevos alfabetismos y las nuevas manifestaciones han ampliado nuestra comprensión de la realidad, al insistir en los procesos dinámicos y de cruces entre códigos y lenguajes (transficcionalidad, intermedialidad, intertexto...). Así, se habla de "transliteracidad" como la capacidad de leer, escribir e interactuar a través de una gama de plataformas, herramientas y medios de comunicación desde la oralidad hasta 
la escritura, televisión, radio y cine, o redes sociales digitales. De hecho, cuando alguien usa un buscador en Internet aparecen todos estos interdiscursos en forma de una amplia gama de lenguajes y textos alusivos al término buscado.

Ante estos nuevos escenarios culturales, necesitamos superar la oposición impresodigital y favorecer un proceso amplio de inclusión cultural, que suponga el fomento de un lector "polialfabetizado" (Alejandro Piscitelli), híbrido, incluso "anfibio" al modo en que Bajtin describe a Rabelais y a Cervantes, esto es, capaz de "pisar varios territorios". Ello supone considerar una ecología integradora, que abarque todas las literacías significativas para la lectura y que contemple tanto las grandes aportaciones de la cultura letrada, incluidos el amor por el libro y la cultura escrita, como la aproximación escrita a todos los fenómenos de la modernidad, incluso a aquellos que serían hoy parte de subculturas marginales o excéntricas respecto a los núcleos científicos y artísticos, pero que en un futuro, según la teoría de los polisistemas de Even-Zohar, bien pueden cambiar de posición. De hecho, la sociología del conocimiento y de las artes ilustra estos casos de recategorizaciones, o cómo unos géneros, autores o textos son despreciados o bien son objeto de culto de forma muy rápida.

En todo caso, la competencia lectora y escritora no solo es clave para participar en ámbitos profesionales, es, ante todo, carta de ciudadanía, es decir, la forma de participar y construir el discurso social, empezando por los imaginarios sociales (Castoriadis) que subyacen al derecho, a las creencias o al ámbito de las costumbres. Olson llamó a esto la "mente letrada", y lo cierto es que volverse letrado es compartir un paradigma, que en nuestros tiempos es a la fuerza un paradigma múltiple, híbrido. Castoriadis distinguió bien esas dos facetas (legein-teukein, referir-actuar), que contrapone los aspectos mentales e intangibles de la lectura a su dimensión corporal, física y contextualizada. Por ejemplo, los juegos de rol y los videojuegos, de tanto éxito entre los jóvenes, evidencian este mismo deseo de integrar lo especulativo-imaginativo con la dimensión lúdica, ostensiva, pues son narraciones que se juegan y recrean hic et nunc.

La cultura letrada ha conformado una gran parte del patrimonio cultural europeo, y por eso nociones como canon o literatura deben seguir siendo fundamentales en cualquier diccionario de lectura, junto con todas las prácticas emergentes de lectura y escritura, desde los blogs a la cibercultura. La modernidad letrada debe asociar estas tecnologías al desarrollo del intelecto en su consideración más totalizadora (por ejemplo, inteligencia emocional). El lenguaje no es algo que se posee como una herramienta más, sino que es algo que "se habita" (Heidegger), y por tanto tenemos que invitar a los neolectores a que descubran los libros y lecturas de todo tipo que quieran "habitar", con la ayuda, en su caso, de mediadores de lectura, no de simples patrocinadores o empresas que canalicen tendencias del mercado. El pensamiento crítico siempre enseña a desconfiar de los significados y estereotipos, y por extensión, también de los "patrocinadores de la alfabetización" (D. Brandt) cuando se presentan de forma excluyente o manipuladora.

Las culturas actuales de la lectura y la escritura, en su diversidad, se acomodan perfectamente a la descripción que hace Bajtin de la cultura de la plaza pública, en toda su dialéctica y en su variabilidad. El permanente "cruce de conversaciones" realmente ha convertido Internet en un sitio donde se entremezclan discursos heterogéneos y donde 
por ello se hace más necesaria que nunca la función del educador, bibliotecarios, padres, esto es, de mediadores.

No se olvide que Bajtin definió una topografía de la cultura popular y contrapuso unos ejes, lo superior-espiritual frente a lo inferior-material. De hecho, las formas libres y exuberantes de expresión han producido una eclosión de manifestaciones en este sentido, por ejemplo, las páginas pornográficas o violentas son el contraejemplo de la síntesis o conciliación que queremos fomentar entre tecnología y humanismo. Cierto que Internet favorece la cultura carnavalesca del doble, la duplicidad de identidad, con el sistema de nicks, identidades virtuales o avatares.

Así que Internet no es solo un gran océano de información, sino que se configura como un gran zoco, un gran mercado, donde las personas, las mercancías y los artefactos fluyen permanentemente, en un ciclo incesante, pues la Red no asume ninguna forma uniforme de organización de la actividad, con calendarios, ni hay ninguna cultura común o koiné, salvo que entendamos por ello la hegemonía cada vez más en cuestión de la cultura occidental. En consecuencia, el reto es relanzar el ideal ilustrado de la "República de las Letras", como un espacio nuevo de rehumanización y potenciación de la lectura. El término "República de las Letras" fue acuñado por Pierre Bayle en 1664 en el título del periódico que él fundó, Nouvelles de la Republique des Lettres. Si bien hay precedentes de esta concepción en épocas anteriores, por ejemplo, en la Universidad de París y su Colegio de Navarra, es con la Ilustración cuando cobra fuerza este ideal de comunidad intelectual universal, sin fronteras fijas y sin ubicaciones concretas (a diferencia de las sociedades y academias).

El modelo ilustrado de un ambiente letrado como el de la República de las Letras tenía como fundamento la circulación libre de las ideas, pues englobaba a todos los hombres letrados, cultos, que intercambiaban ideas. Este intercambio se producía sobre todo en los ambientes apropiados, tales como los salones y tertulias, y alumbró por ello nuevos modos y prácticas de sociabilidad al amparo de estas actividades intelectuales. Por ejemplo, aparece de forma destacada el debate sobre el papel de la mujer: en París, en los salones y convites, se da lo que Roger Chartier llama de forma muy acertada "el gobierno de las mujeres y la compañía de personas ingeniosas". Pues bien, los nuevos lectores del siglo XXI ya no son solamente estos nuevos públicos emergentes del siglo XIX, como la mujer o los niños, sino la inmensa mayoría de la humanidad que ha sufrido la exclusión cultural, asociada lógicamente a su marginación social, política y económica.

Finalizando con otra referencia más a Bajtin, la República de las Letras se asentaba sobre un ámbito prioritariamente conversacional y va ligada a las condiciones materiales e ideológicas de la época: la lectura dialógica o convivencial que hoy podamos hacer, como formas herederas de esta visión abierta, no debe hacernos olvidar lo específico de cada momento histórico: hoy la alfabetización pionera no se hace en los salones de moda, pero sí en escenarios educativos y culturales emergentes, por ejemplo, en proyectos de intervención en ciudades (La Nuit Blanche), festivales de artes, etc.

En suma, la relación entre lectura y cultura emprendedora es total, se lee o se escribe a partir de unas experiencias previas y eso genera otros ámbitos y otros "derivajes" que llevan a las personas y a los grupos a identificarse con ciertas demandas o innovaciones de su entorno. 
Por ello queremos que este diccionario sea no un simple glosario, sino que invitamos a habitarlo como si fuera una casa de la lectura, en el sentido de encontrar esos espacios y referencias singulares de una cultura en continuo cambio. Más de 90 expertos de 27 universidades han creado estas pequeñas ventanas por las que asomarse a una realidad compleja y apasionante.

\section{EL APARATO DESCRIPTIVO}

Conforme a la misma idea de eclecticismo que venimos preconizando, hemos optado por un sistema mixto que reuniera las ventajas de un diccionario alfabético al uso, pero con una organización en cierto modo similar a la de un diccionario ideológico.

Nos hemos apoyado en el Mapa cartográfico conceptual de la cultura escrita en el Quijote que Aitana Martos García instrumentó (en el marco de la tesis doctoral dirigida por Agustín Vivas) a partir de cuatro dominios o macrocampos, que inventariaban los conceptos y describían sus interrelaciones, desde la noción de "cuadrícula social” (Douglas) y en relación con la teoría de "campo" del sociólogo Pierre Bourdieu (1996), como un espacio social de acción y de influencia en el que confluyen relaciones y estructuras sociales determinadas.

En el ámbito específico de la cultura escrita, esta distribución revela la distinción del ecosistema de la lectura en cuatro dominios principales: "creación" (ingenio), "educativos" (en sentido amplio, instrucción), "clasificadores" (preservación) y "productivosdistributivos-consumido-res" (materialidad):

Mapa cartográfico conceptual de la cultura escrita en el Quijote

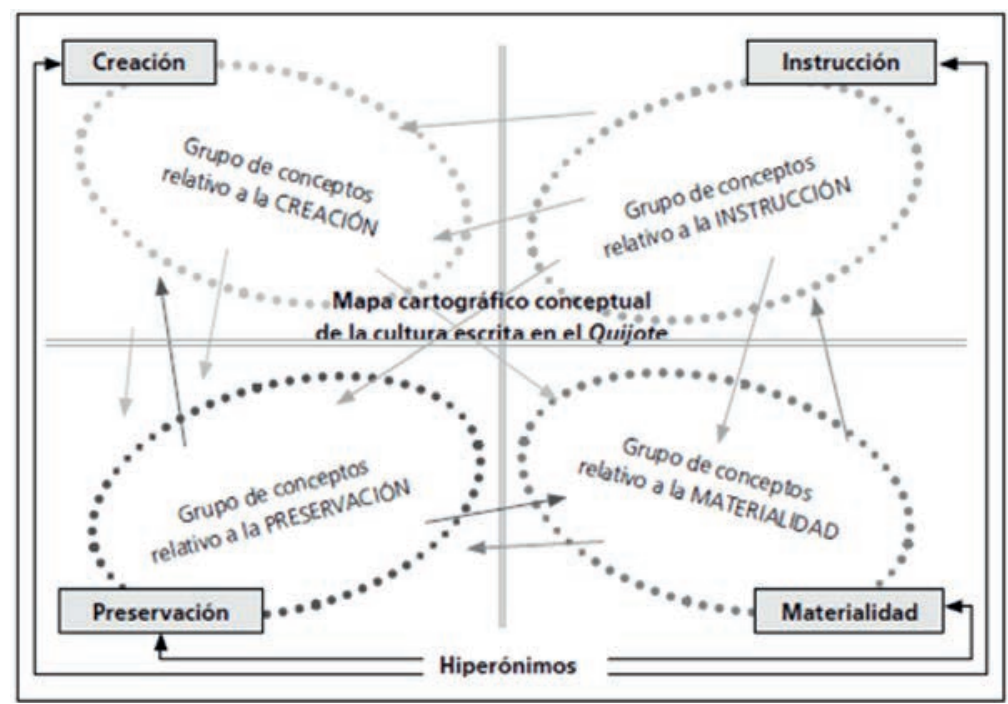


Una primera transposición de este esquema a las categorías del diccionario se puede observar en los cuadros sinópticos de las páginas 680 a 683 de este Diccionario.

Aparte de la conceptualización que supone este dispositivo analítico, lo que más nos interesa es su capacidad heurística. Por ejemplo, los dominios A y B se contraponen a C y D con relación al eje intangible-tangible: en unos casos hablamos de textos, creaciones, signos; en los otros, de documentos, productos, libros..., y sus entrecruzamientos ponen de manifiesto la dinámica ya subrayada por Chartier y McKenzie: "materialidad del texto" - "textualidad del libro".

El campo del ingenio es el campo de la expresión ahormada, del talento, de la creación, de lo que hoy llamaríamos el "emprendimiento". Así pues, las zonas del ingenio y de la instrucción tienen más que ver con la esfera intangible, con los procesos y la generación de contenidos, y afectan por tanto a los valores, los individuos, la alfabetización como socialización y sus patrocinadores. Trasladado al plano actual, en esta cultura de la creación, el ingenio o el emprendimiento, los participantes potenciales son escritores noveles, jóvenes y toda clase de ciudadanos; sus escenarios pueden ser la calle, el teatro, los cafés, los espacios juveniles; los artefactos pueden ser los libros, pero sin duda aparecen muchos otros gadgets, dispositivos electrónicos, novelas gráficas, esto es, textos influidos cada vez por la intermedialidad; final-mente, las actividades o rutinas ya no se encapsulan en los formatos clásicos, pues los talleres, perfomances y otros tipos de actividades se combinan con las actividades convencionales de recitales, presentaciones de libros..., y en ellas se practican formas alternativas, como la escritura creativa, o la colaborativa.

En cuanto al dominio de la instrucción, la historiografía de la lectura ha fijado las formas dominantes de la cultura letrada en tiempos del Quijote, y en eso la diferencia no sería muy acusada. Tenemos mediadores semejantes, es decir, educadores, académicos, o, en su término clásico, letrados. Y tenemos también unas instituciones de enseñanza básica y superior que, en su articulación actual, no difieren demasiado de las de la época clásica, aunque sí en sus contenidos o metodologías. En absoluto quiere decir esto que no pueda haber emprendimiento e innovación en el seno de las instituciones, si bien las instituciones arrastran una tradición y una dinámica distinta, menos fluida o permeable, por ejemplo a la innovación social, la creatividad, etc.

Los dominios inferiores de la cuadrícula se refieren a dos ámbitos propios, la conservación-preservación o memoria (“cultura como memoria”, Lotman), entendiendo que la alfabetización funciona también como un legado o patrimonio que hay que organizar, y tiene una dimensión museística, por tanto, tangible. Concierne, pues, al mundo de la biblioteca y del archivo, pero también a todos los objetos y lugares asociados al mundo de la cultura escrita (los "lugares de memoria" de Pierre Nora), por los cuales se perpetúa, y en este sentido enlaza con las nuevas corrientes (Pahl y Roswell) que reivindican el papel de la cultura material y, por tanto, de los múltiples objetos y artefactos de la vida corriente en la alfabetización contemporánea.

Por último, cabe subrayar que esta distribución es heurística y en absoluto exhaustiva, en la medida en que permite agregar conceptos y conexiones que en esta versión del diccionario no han podido explicitarse por diversos motivos, por ejemplo, no contar la Red con expertos suficientes en determinados ámbitos. Por ello mismo, al igual que 
no todos los fenómenos culturales emergentes forman parte del "catálogo" conceptual, también hay ámbitos concretos que no se han incorporado aún en esta edición; así, la literatura italiana, o determinados fenómenos culturales latinoamericanos, son entradas que en el futuro, junto con muchas otras, completarán este proyecto que, invocando nuevamente a Bajtin, pretende ser polifónico y dialógico. Pretendemos que cada versión del diccionario que se elabore en los próximos años desde las distintas universidades y países de la Red sea un palimpsesto, una reescritura continua del mundo de la lectura desde los conceptos y paradigmas con que intentamos describirlo, comprenderlo y transformarlo en cada momento histórico, conscientes de que una sociedad plenamente alfabetizada -en cantidad y en calidad- será una sociedad más democrática y mejor preparada para los retos del futuro.

Para más información: http://universidadeslectoras.org/proyectos/Diccionario-de-lecturaRIUL/196

La versión digital está accesible a través del Proyecto DINLE de la Universidad de Salamanca: http://dinle.usal.es/ 